\title{
Prácticas abusivas de los proveedores y el deber de trato equitativo $y$ digno al consumidor
}

\section{Suppliers' Abusive Practices and Consumers' Right to Fair and Decent Treatment}

Carlos Eduardo Tambussi*

DOI: http://dx.doi.org/10.21503/lex.v16i21.1545

* Carlos Eduardo Tambussi: Abogado, Universidad de Buenos Aires (1991), Procurador Adjunto de Asuntos Patrimoniales y Fiscales del Gobierno de la Ciudad Autónoma de Buenos Aires (2010-2012). Secretario del Juzgado Nro. 18 Secretaria 35 del Fuero Contencioso Administrativo y Tributario de la CABA (2013-actualidad). Profesor Adjunto Regular: Universidad de Buenos Aires, Facultad de Derecho. Cátedra: Dr. Roberto Saba. Asignatura: Derechos Humanos y Garantías. Profesor a cargo de curso "Protección Constitucional de Consumidores y Usuarios" del Ciclo Profesional Orientado en la Facultad de Derecho (UBA). Docente en seminarios y cursos de posgrado sobre Derechos de Consumidores y Usuarios. Presidente de la Comisión de Derecho del Consumidor de la Asociación de Abogados de Buenos Aires.

Correo electrónico: cetambu@uolsinectis.com.ar.

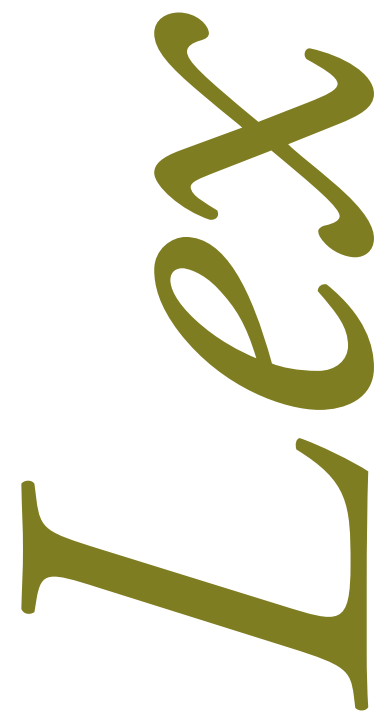




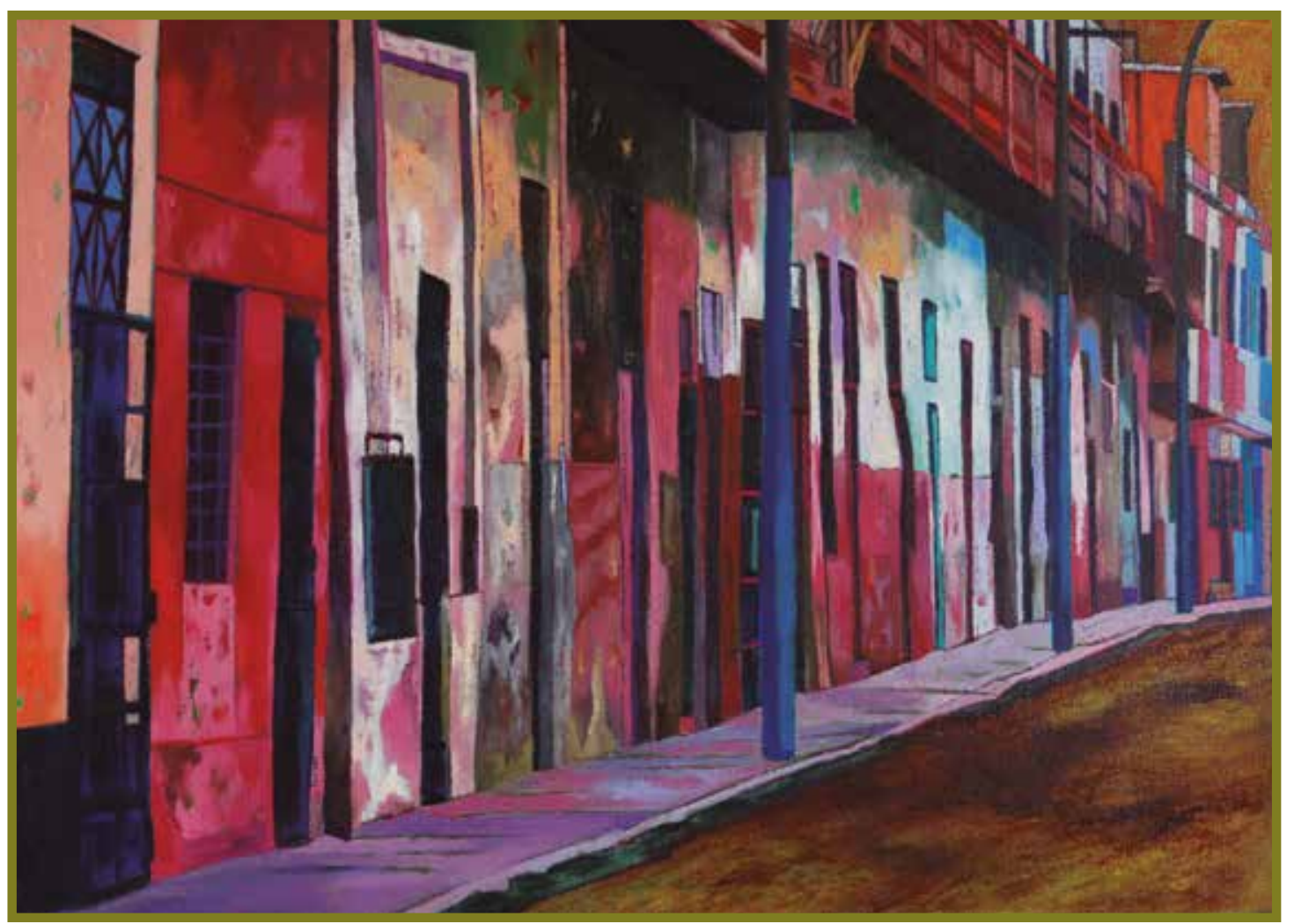

Barrios Altos. Enrique Polanco.

https://www.facebook.com/enriquepolancopintor/ 


\section{RESUMEN}

Las llamadas "prácticas abusivas" en el derecho del consumo son las conductas de los proveedores que menoscaban el deber de trato equitativo y digno que deben al consumidor. Su presencia es cotidiana, su efecto es lesivo. En este trabajo nos referiremos a las prácticas más habituales, causadas por la concepción empresaria de maximización de beneficios en demérito del débil en la relación jurídica. Algunas de ellas impiden el acceso al consumo, como la imposición forzosa de la tecnología. Otras, están presentes desde el mismo origen del proceso productivo, como la obsolescencia programada. Derivadas del marketing analizaremos la inducción cultural al consumo y la publicidad no deseada. Relacionadas en forma directa con el trato equitativo y digno contemplaremos atención personalizada y las esperas en el establecimiento del proveedor. Finalmente nos referiremos a la abusividad en los precios en relación con los bienes y servicios.

Palabras clave: derechos del consumidor, trato equitativo y digno, práctica abusiva, tecnología, obsolescencia, inducción cultural, publicidad, atención al consumidor, precios abusivos.

\section{ABSTRACT}

In Consumer Rights' Law, "abusive practices" concerning providers are conducts that prejudice consumers' right to conditions of equitable and dignified treatment. In this essay, we will discuss most frequent practices that are rooted in companies' goal to maximize benefits prejudicing the most weak party of the contractual relationship. Some of them prevent access to consumption, such as compulsory use of technology. Others are present in the precise origen of the productive process, such as programmed obsolescence. Derived from marketing, we will analize cultural induction to consume and undesired advertisement. Directly related to equitable and dignified treatment, we will focus on personalized assistance and waiting times at providers' facilities. Finally we will deal with abuse in prices of goods and services.

Key words: Consumer rights, equitable and dignified treatment, abusive practices, technology, obsolescence, cultural induction, advertisement, consumers assistance, abusive prices. 


\section{CONTEMPLACIÓN LEGAL DE LAS PRÁCTICAS ABUSIVAS:}

El Código Civil y Comercial de la Nación Argentina contempla las prácticas abusivas en el artículo 1096. Las mismas no están definidas en la normativa, por lo que entendemos que se trata de una voz comprensiva de toda manifestación de la profesión mercantil, cualquier hecho generado por los proveedores vinculado a su actividad y que pueda afectar a un sujeto expuesto a la misma, que tendrá la posibilidad de reclamar por el respeto a sus derechos.

Por tanto, y aunque no exista definición conceptual, lo cierto es que la doctrina y la jurisprudencia venían extendiendo la aplicación del concepto de cláusula abusiva a aquellas prácticas comerciales que importan una desventaja comparativa para el consumidor, ya sea porque se vea afectada su capacidad de discernimiento para ejercer la elección del producto o servicio a adquirir, o que por las particularidades a través de las cuales el proveedor oferta sus productos o servicios los consumidores resulten alcanzados por prácticas vejatorias, intimidatorias y/o discriminatorias de todo tipo, que son muchas veces verificables en la práctica cotidiana.

Determinar si una cláusula predispuesta es abusiva y en qué medida puede morigerarse o declararse nula requiere que ella sea interpretada, a fin de desentrañar su sentido y alcance y adecuarla al contexto del contrato y a lo que es de uso y práctica en contratos de esa naturaleza (Art. 218, Inc. $6^{\circ}$, Cód. de Comercio), y en tal sentido las cláusulas abusivas deben hallar su adecuado remedio en la observancia de la buena fe contractual para restablecer la relación de equidad, conforme el principio del Art. 1198 del Cód. Civil ${ }^{1}$.

Se trata, en suma, de prácticas de comercialización que vulneran el derecho del consumidor a un trato equitativo y digno o afectan la libertad de elección o transgreden el principio de buena fe o importen abuso del derecho. Seńala la doctrina que no se reducen a "prácticas de

1 Cámara 1a de Apelaciones en lo Civil y Comercial de Mar del Plata, sala II , Martinelli, José A. c. Banco del Buen Ayre, 20/11/1997, LLBA 1998, 511. 
comercialización sino todas las "prácticas empresariales" y que "tratan de obtener una maximización de la tasa de beneficio o ganancia sin causa, vulnerando así la equidad económica”2. También han sido definidas como "las que enferman al mercado"3.

Por su parte, dentro del mismo capítulo se consagra en el Código Civil y Comercial el trato equitativo y digno, ya incluido en el art. 8 bis del estatuto especial o ley 24240.

En el cuerpo unificado se incorpora el concepto de dignidad conforme los tratados internacionales de derechos humanos ${ }^{4}$, incluso los que tienen jerarquía constitucional conforme el Art. 75 inciso 22 de la Carta Magna, en otra clara muestra de la condición del consumo como perteneciente a esa categoría. Guarda relación y correspondencia con lo establecido en el artículo 1 del Código ${ }^{5}$ respecto a la normativa aplicable para la solución de controversias, y con la letra del artículo $2^{6}$, que establece que los tratados de derechos humanos son pauta insoslayable para la interpretación de la ley.

En particular, "dignidad", se entiende como "cualidad de digno", del latino dignus, que se traduce por "valioso". La dignidad es un atributo exclusivo del ser humano como valor intrínseco y supremo que tiene cada persona independientemente de su situación económica, social y cultural, así como de sus creencias o forma de pensar. Es el fundamento de todos los demás valores y, en definitiva, de todos los derechos individuales. Es lo que liga al individuo a la familia humana ${ }^{7}$ y es un principio material de interpretación de los derechos fundamentales, destinada también a servir de reacción frente a los abusos del mercado.

La expresión supralegal de trato equitativo y digno se hace operativa a través de la obligación impuesta a los proveedores de garantizarlo a los consumidores y usuarios, mediante la abstención de conductas que los coloquen en situaciones vejatorias, vergonzantes o intimidatorias.

2 Celia Weingarten - Carlos Alberto Ghersi, "Principios esenciales en la prestación de servicios masivos", Diario La Ley 06/12/2010, 1.

3 Véase Kemelmajer de Carlucci, Aida: "Prácticas abusivas en los contratos de consumo", Suplemento Especial Esp. Nuevo Código Civil y Comercial de la Nación. Contratos 2015 (febrero), 237.

4 Art. XXXIII de la Declaración Americana de los Derechos y Deberes del Hombre, los Arts. 1 y 22 de la Declaración Universal de Derechos Humanos, el Pacto Internacional de Derechos Económicos, Sociales y Culturales, el Art. 10 del Pacto Internacional de Derechos Civiles y Políticos, los Arts. 5 y 11 del Pacto de San José de Costa Rica, y el Art. 23 de la Convención sobre los Derechos del Niño, entre otros.

5 Artículo 1.- Fuentes y aplicación. Los casos que este Código rige deben ser resueltos según las leyes que resulten aplicables, conforme con la Constitución Nacional y los tratados de derechos humanos en los que la República sea parte. A tal efecto, se tendrá en cuenta la finalidad de la norma. Los usos, prácticas y costumbres son vinculantes cuando las leyes o los interesados se refieren a ellos o en situaciones no regladas legalmente, siempre que no sean contrarios a derecho.

6 Artículo 2.- Interpretación. La ley debe ser interpretada teniendo en cuenta sus palabras, sus finalidades, las leyes análogas, las disposiciones que surgen de los tratados sobre derechos humanos, los principios y los valores jurídicos, de modo coherente con todo el ordenamiento.

7 Véase Miguel F. De Lorenzo, “Contratos, derechos fundamentales y dignidad de la persona humana”, La Ley 2011-E, 1258. 
El cumplimiento de estas garantías debe verificarse en el caso concreto, encontrándose todo proveedor obligado a su observancia, el estado a velar por su cumplimiento (y a respetarlo cuando actúe como proveedor), y se extiende a los aspectos anteriores, concomitantes y posteriores a la realización del acto de consumo, es decir todos los aspectos fácticos de todas y cada una de las etapas del "iter" de la relación de consumo, comprendiendo tanto el trato durante ese decurso, como los supuestos donde no hay contacto directo (publicidad, ofertas, y otros). La obligación tiene varios frentes, ya que se impone tanto en cabeza del proveedor el respeto a los valores señalados, y al estado el deber de garantizar su observancia. Incluimos desde luego su afirmación como derecho del consumidor y por ende a su exigibilidad.

\section{ESTADO - SITUACIÓN:}

Si bien el papel del consumidor frente a las empresas ha evolucionado con el paso de los años, también se ha perfeccionado el marketing salvaje y fundamentalismo de las ventas a cualquier costo o mejor dicho a cualquier procedimiento, que puede ir desde el acoso hasta la utilización de la confusión permanente del cliente paradójicamente como constructora de la decisión de consumir (de contratar la adquisición de un bien o la prestación de un servicio) ${ }^{8}$.

Un planteamiento del problema a los fines de buscarle una posición de fuerza a los consumidores es su existencia misma: si no hubiera consumidores, no existirían las empresas. Pero no alcanza. Ellas saben que tienen lo que las personas buscan y necesitan. Así es que trabajan tanto sobre necesidades reales como en la estrategia de crearlas o hacerlas sentir en sus destinatarios, ocupando este último detalle un papel importante en las tácticas de los procesos que llevan a cabo los proveedores para atraer, ganar y lo más importante, satisfacer las necesidades de los clientes (insisto: reales o artificiosamente creadas). Esa creación consiste en apuntar a que baje la autoestima del consumidor si éste no obtiene el producto, en ocasiones llegándolos convertir en consumidores compulsivos, los cuales dependen de ese producto para "sentirse bien". Eso explica en parte como en aún determinadas situaciones de agudas crisis (o presentadas como tales) se genera cierto hiperconsumo y sobreendeudamiento.

La garantía comporta entonces, un conjunto de mediaciones, actitudes y prácticas, que en la relación de consumo debe tomar el proveedor para que la misma se encuentre libre de humillaciones, frustraciones o exclusiones injustificadas para el consumidor. El trato digno para la ley, deja de depender de la amabilidad, cortesía o de la política comercial del prestatario, y pasa a ser una práctica de reconocimiento exigible para el consumidor y obligatoria para el prestador. El contenido concreto del ámbito protegido, no es taxativo y alcanza distintas dimensiones asociadas al trato humano, la libertad en la relación de consumo, la buena fe y la prohibición del abuso de derecho (art. 8 y 10 del Código Civil y Comercial).

8 Véase nuestra opinión en Carlos Tambussi, Liliana Araldi y Mariana Baigorria, "La responsabilidad social empresaria y los derechos del consumidor”, Diario La Ley 6 y 7 de enero de 2014. Cita On Line: AR/DOC/3999/2013. 
Por su parte, el artículo 1098 del Código se refiere al principio de no discriminación, también en consonancia con el artículo 8 bis del estatuto especial.

La discriminación en sentido despectivo y contrario a los derechos humanos consiste en hacer la distinción en base a criterios arbitrarios que impliquen minusvaloración o trato de inferioridad, como ha sucedido en el decisorio que comentamos, que señala que las normas de consumo pueden conjugarse al aplicarse a las consecuencias del acto discriminatorio al consumidor con las previsiones tanto civiles como penales de la ley 23592, conocida como "ley antidiscriminatoria", extendiéndose también a supuestos post contractuales.

Las muchas veces habituales prácticas discriminatorias en materia de consumo, quizás sean la forma más perversa de actuación de las empresas, ya que no están escritas en los contratos y resultan de la práctica o de premeditadas políticas de marketing, y que son una cuestión invisible y lacerante para el ser humano, aspecto éste que nos remite una vez más a la protección de derechos humanos elementales y resulta más evidente en los casos de los consumidores más débiles por sus condiciones objetivas frente a la relación de consumo por su vulnerabilidad mayor (personas con capacidades diferentes, niños, ancianos, analfabetos, extranjeros, u otros).

Los proveedores o prestadores deben garantizar al consumidor un trato que debe reunir los recaudos de ser digno y equitativo, lo cual implica no sólo abstención de lo contrario sino adoptar también medidas positivas' que involucran la organización del servicio, la remoción de obstáculos y la prevención de indignidades, para que el consumidor se encuentre libre de humillaciones, frustraciones o exclusiones injustificadas.

El alcance de la obligación importa: a) un trato respetuoso y considerado, libre de insultos, descalificaciones u otras desconsideraciones o menosprecios; b) una atención comprometida, eficiente, responsable y oportuna; c) una estructura de medios -infraestructura, personal etc.adecuada al consumidor y al servicio que se presta; f) un trato que respete la privacidad y la intimidad de la persona y no la someta al prejuicio de terceros; y g) un trato sin discriminaciones. Desarrollaremos a continuación algunos supuestos de prácticas abusivas relacionadas con los más recientes fenómenos del mundo del consumo y la comercialización.

\section{EL ABUSO DE LA “TECNOLOGIZACIÓN FORZOSA”:}

Este aspecto muchas veces proviene de la misma normativa. El progreso del acceso a datos y a sistemas de información y comercialización parece presentarse a veces como inversamente proporcional a la vigencia de los derechos y el respeto a los consumidores. Esto puede verse, por ejemplo, en la saturación comunicativa. Se dice que un ciudadano de una ciudad de tamaño medio recibe alrededor de 1500 mensajes comerciales al día a través de diferentes canales y en distintos formatos. 
En materia de comercio electrónico, el Código Civil y Comercial del año 2015 en su art. 1104 replica el art. 32 de la ley de defensa del consumidor 24240 y dentro del tratamiento de las "modalidades especiales" replica la original regulación de las "ventas fuera del establecimiento comercial", pero a la vez introduce la primera normativa nacional respecto a la contratación electrónica. La preceptiva sobre ventas fuera del establecimiento del proveedor tiene la finalidad de cubrir las realizadas tanto el domicilio del consumidor mismo o su lugar de trabajo, la vía pública, la correspondencia (en sentido amplio en cuanto a medio empleado) y la invitación con otro objetivo, todas prácticas comerciales de fuerte arraigo, donde muchas veces el consumidor es atropellado en sus posibilidades de reflexión, mediante políticas de marketing que sin dudas son enseñadas en las facultades y que significan entrometimientos, muchas veces acosadores o intimidantes e invasivos de la privacidad, que realizan las empresas a fin de inducir a la contratación en ámbitos que para el consumidor son pocos reflexivos, o no propicios a los fines de un correcto discernimiento y comprensión de las características, alcances y sobre todo costos de lo que se está contratando. La novedad irrumpe con el art. 1105 que refiere a los convenios logrados entre proveedor y consumidor con el uso exclusivo de medios de comunicación a distancia que se definen como aquellos que pueden ser utilizados sin la presencia física simultánea de las partes contratantes.

A través de los medios electrónicos la vulnerabilidad natural del consumidor aumenta ${ }^{9}$, ya que se ofrecen solamente imágenes de los productos que no siempre se corresponden con la realidad o no permiten apreciar claramente las calidades o tamaños, texturas y demás características. A la par, se ofrecen importantes descuentos si se contrata por esta modalidad o en algunos casos es la única mecánica de contratación. Sin duda la tecnología aumenta la vulnerabilidad de los consumidores, y hasta en algunos aspectos puede ser excluyente, dado que para perfeccionar una contratación se requieren conocimientos, habilidades o "experiencia” informática, que no todas las personas de todas las edades están en condiciones de reunir. Las oportunidades u ofertas por Internet, en este sentido, dejan "fuera" a quienes no indagan o buscan ocasiones de consumos por este medio, simplemente porque no saben manejarlo, o aun sabiéndolo, reniegan de las dificultades de su implementación. En estos contratos tanto la negociación como la conclusión de la contratación o pago se efectúa electrónicamente, y el consentimiento se manifiesta manipulando un teclado, generalmente debiendo adherir a extensas condiciones generales, lo cual hace aplicable al caso el fenómeno regulador de los contratos de adhesión, ya que todo el sistema responde al criterio de organización del proveedor. Entendemos que es un error entender que en la venta electrónica no necesariamente existe debilidad subjetiva del consumidor. Se necesitan ciertas cualidades para afrontar la contratación on line, por lo que la debilidad natural del protagonista de este

9 Véase nuestra opinión en Carlos Tambussi, "Del soporte electrónico y la forma en los contratos a distancia" DPI Cuántico. Diario DPI Consumidores y Usuarios Ańo 2, No 50, 20 de octubre de 2015. 
derecho estaría atenuada en estas modalidades. Tampoco que no exista el factor sorpresa, por ser el consumidor el que toma la iniciativa. La ingeniería de las implementaciones de estos contratos y la realidad lo demuestra, es capaz de superar las habilidades informáticas medianamente desarrolladas, y las sorpresas quizá no surjan de la iniciativa que las excluye, sino a posteriori de la invitación a contratar, en cuanto a las puestas en marcha en la práctica de las etapas o aperturas de pantallas diseñadas por el proveedor para concretar el negocio. En esa línea, hemos criticado que el art. 1106 haya establecido que "siempre que en este Código o en leyes especiales se exija que el contrato conste por escrito, este requisito se debe entender satisfecho si el contrato con el consumidor o usuario contiene un soporte electrónico u otra tecnología similar". Siendo la forma una exteriorización de la voluntad, no debe faltar en los contratos, donde no puede dejar de plasmarse en el "mundo sensible" la conjunción de voluntades. Si bien la nueva codificación, en sus artículos 1015 y 969 consagran la libertad de formas, también impone en algunos casos una forma determinada, como la escrita o en escritura pública (Art. 1017) que se prevé, por ejemplo, para la compraventa de inmuebles, alcanzada por la ley de defensa del consumidor. Lo mismo sucede en el estatuto especial para para determinados documentos (Art.. 14 - certificado de garantía-, Art.. 20 -pacto por escrito respecto de los materiales a usar en la reparación-, Art.. 23 -deficiencias en la prestación del servicio-, Art.. 24 -garantías por servicios-, Art.. 30 bis -constancias por escrito de inexistencia de deudas por servicios públicos domiciliarios-) y Art. 34 -deber del proveedor de informar por escrito el derecho de revocación-. Así, considerar que la forma escrita legalmente exigida se debe entender satisfecha si el contrato con el consumidor o usuario contiene un soporte electrónico u otra tecnología similar puede arrojar algunos graves problemas de concordancia e interpretación, a más de dificultades probatorias para la verificación de la autenticidad o carácter inalterable de soportes informáticos u otros elementos tecnológicos y ser un factor de inseguridad para las contrataciones y de inestabilidad de los derechos protegidos a los consumidores.

En cuanto a la tecnologización forzosa y su influencia en el derecho a la información, una reciente modificación por decreto de necesidad y urgencia ${ }^{10}$ al art. 4 del estatuto del consumidor, estableciéndose que:

"La información debe ser siempre gratuita para el consumidor y proporcionada en el soporte que el proveedor determine, salvo que el consumidor opte por el soporte físico. En caso de no encontrarse determinado el soporte, este deberá ser electrónico".

Con lo que se revierte la premisa de la normativa anterior, donde el punto de partida era el soporte físico salvo que el consumidor optara por recibir la información por vía electrónica.

10 Decreto de Necesidad y Urgencia 27/2018. 
Entendemos que en su esencia y trascendencia el adelanto tecnológico es un paso adelante para la difusión de la información y para la agilización de las cuestiones atinentes a la implementación de la relación de consumo. Pero también que en un derecho tuitivo y equilibrador como es el de usuarios y consumidores, desandar el camino anterior y conferir al proveedor la posibilidad de "establecer el soporte", es un retroceso protectorio.

Es que pese a la acentuada generalización y evolución del mundo cibernético, aun el papel (o «soporte papel», que la modificación llama «soporte físico») sigue siendo un factor de certeza. Hay un amplio camino intermedio entre la necesaria e imprescindible recepción del mundo tecnológico por parte de la legislación y las metodologías que se van considerando legalmente válidas para diversos fines.

Y hay que tener en cuenta que todavía están vivas generaciones que no tienen familiaridad informática y que estarán obligadas a hacer uso de la opción por el soporte físico, imponiéndose a su cargo la diligencia necesaria para modificar la modalidad electrónica que imponga el proveedor que es el presupuesto legal, haciendo uso de la opción para lo cual el legislador no ha previsto mecanismos concretos para implementarla. Hay personas que no tienen acceso a las nuevas tecnologías ya sea por su posición sociocultural, razones de edad avanzada, o simplemente desinterés a ingresar en el sistema informático ${ }^{11}$. Sin embargo, ya en la actualidad, para ellos, muchas veces la única forma de contratación de ciertos servicios es la web.

En otras palabras, no tenemos por prudente la sujeción del universo de la relación de consumo al mundo on line a sola voluntad del proveedor ni la imposición del deber de evitar esto manifestándose en contrario. Es refractario a los principios protectorios del régimen tuitivo, y a la vigencia de los derechos constitucionales en juego, que deba ser el consumidor quien deba manifestarse en contrario del medio utilizado por el más poderoso de la relación. El Estado debe aparecer para poner freno a los abusos del mercado, pero tal objetivo no ha de cumplirse imponiendo cargas al consumidor.

\section{LA OBSOLESCENCIA PROGRAMADA Y LA INDUCCIÓN CULTURAL AL CONSUMO:}

Otra manifestación más estructural y que se ubica antes de la comercialización y en el mismísimo proceso productivo es aquella que nos deja la evidencia acerca que los productos/ servicios tienen un ciclo de vida cada vez más corto, con lo cual es difícil llegar a la identificación plena de los mismos. Los cambios en la moda son cada vez más rápidos y las nuevas tecnologías dejan obsoletos productos que poco tiempo atrás eran innovaciones, creando una "cultura de lo desechable", a la vez que una verdadera "inducción cultural al consumo",

11 Véase Federico Manuel Álvarez Larrondo, "Ley 27.250: El deber de información en soporte papel”, DPI Cuántico. Diario Consumidores y Usuarios Nro. 79, 21.06.2016. 
donde siempre el articulo nuevo (y más caro) tendrá un precio mayor y será nuevo no solo por su no uso, sino por sus reales o aparentes innovaciones, pocas veces sustanciales, las mas de las ocasiones, cosméticas.

La llamada "globalización" del mercado importa la homogeneización e internacionalización de los patrones de consumo y producción por encima de las fronteras. Este fenómeno pervive en unificar las necesidades creadas de la gente, estableciendo las mismas pautas y los mismos usos a nivel mundial, diluyendo las identidades nacionales que se definían, también, por un tipo y modo de consumo. Consumir lo propio constituía una parte de la pertenencia que se ha perdido, en esta idea que propone que todos consumamos lo mismo y de la misma manera. Implica, a su vez, una transformación constante en la tecnología de producción y diseño de los bienes, generando una ampliación muchas veces artificiosa e inducida de los deseos y expectativas materiales ${ }^{12}$ a su respecto. La obsolescencia acelerada de los productos más vinculados con adelantos tecnológicos, pensada respecto de la calidad de los materiales empleados, dosificada en forma convenientemente y al servicio del marketing provoca una sensación a veces artificial de retraso y e ilusión y a la par necesidad de realizar un nuevo consumo para actualizarse, pertenecer, estar al día. Sin dudas este fenómeno encierra una "interacción funcional de actividades económicas y culturales dispersas, de bienes y servicios generados por un sistema con muchos centros"13. La globalización trajo fuerte aumento del desarrollo tecnológico, y consiguiente incremento del poder de sus propietarios, los dueños del desarrollo. Lo que se tiene se vuelve a cada instante obsoleto o fugaz. Cada vez es artificiosamente demasiado tarde más temprano.

En ese panorama, mencionaremos dos aspectos que son distintivos del signo de los tiempos:

La inducción cultural del consumo hace que se confundan necesidades con deseos y que en algunos casos consumos no imprescindibles se conviertan en demandas culturalmente determinadas y condicionadas, a través del desarrollo pautado de la innovación con salidas al mercado de productos que "envejecen" a los anteriores, a la par que se "discontinúan" los productos "viejos".

La segunda gran inductividad reside en la moda, que deriva en forma inmediata pero hacia lo que parecen pasados remotos, determinados modos de consumo que son obligados a ser reemplazados por nuevos, fenómeno cuyo icono quizá sea la indumentaria.

12 Véase nuestra opinión en Carlos Tambussi, "Sobre la necesidad de actuar ante el fenómeno de la obsolescencia programada" en elDial cita DC202C.

13 Nestor García Canclini, Néstor, Consumidores y Ciudadanos, conflictos multiculturales de la globalización (Grijalbo, México, 2000), 23. 
La práctica arraiga en que el consumidor no es un ser aislado, sino que se encuentra inmerso y condicionado socialmente. Hay también aspectos iconográficos y estéticos en el consumo, dado que la posesión de cosas enuncia hacia afuera un signo de status, una personalidad determinada, una repercusión social. Se construye un paradigma donde los pertenecientes comen, se divierten, estudian, se visten, habitan, viajan, de una manera determinada, consultan o consumen determinados medios de comunicación. La sociedad humana impone a sus miembros -otra vez- principalmente la obligación de ser consumidores. La forma en que esta sociedad moldea a sus integrantes está regida, ante todo y en primer lugar, por la necesidad de desempeñar ese papel: la norma que les impone, la de tener capacidad y voluntad de consumir ${ }^{14}$.

Este mecanismo es inductivo del inconsciente, y para alcanzar ese logro, trajo consigo el surgimiento del fenómeno del sobreendeudamiento del consumidor, que puede llegar a sobrepasar su capacidad de pago en aras de una carrera contra múltiples consumos muchas veces suntuarios.

Por su parte, la obsolescencia programada es una práctica empresaria que consiste en utilizar técnicas para acortar la vida de un bien con el fin que el consumidor tenga que reemplazarlo bien pronto, y comprende la utilización de piezas o repuestos pensados con vida útil muy limitada para convertir al producto en inutilizable, obsoleto o inservible en un lapso premeditado, mucho menor al técnicamente posible, a partir de lo cual la fabricación y/o provisión de los repuestos se discontinua, y deja como resultante la única posibilidad de acudir al producto nuevo, lógica y sensiblemente más caro.

En otras palabras, su existencia versa sobre una estimulación artificial de la demanda, mediante el arrojo al consumidor a comprar (de modo programado) productos nuevos si desea seguir cubriendo la necesidad en juego. Ese sentimiento obligatorio inducido se traduce, además del precio mucho mayor de la novedad, con las muchas veces dudosa o significativa calidad e importancia de la innovación contenida en el producto de repentina y publicitada aparición como innovador. La obsolescencia programada afecta el poder adquisitivo del consumidor.

Como práctica empresaria, consiste en la determinación o programación del fin de la vida útil de un producto o servicio, calculada de antemano por el fabricante desde su propia fase de diseño. Es una conducta perjudicial para el consumidor y beneficiosa para el sector empresarial, que se enriquece por la estimulación al consumidor a comprar de modo acelerado en forma ficticia e innecesaria productos nuevos para cubrir necesidades que pueden resultarles muy importantes.

14 Véase Esteban Javier Arias Cáu y Sergio Sebastián Barocelli, "El sobreendeudamiento del consumidor y la adicción al consumo", en Microjuris Cita: MJ-DOC-6461-AR MJD6461. 
Cognoscitivamente, el consumidor no tiene en cuenta a priori este fenómeno a la hora de contratar o decidir, y no lo percibe como dato al realizar una decisión de compra, sencillamente porque nunca le es informado, gobernándose en sus inclinaciones por las características y el nivel de confianza en el producto o la marca. De tener en cuenta a la obsolescencia programada o al menos información sobre la vida útil del producto, sería posible que el consumidor agregue el dato a sus consideraciones y elija dirigirse a competidores en busca de los factores calidad, duración y por supuesto, precio.

En óptica empresarial, va de suyo que el objetivo es el beneficio económico. Importa abaratamiento de costos al usar componentes o materiales más baratos, a la vez que compromete el éxito comercial de los productos en algunos casos, cuando la programación mezquina afecte los procesos de fabricación ${ }^{15}$. El carácter pernicioso - lucrativo se complementa con la política de encarecimiento de los repuestos y la nula o poco especializada mano de obra en materia de reparaciones, que hacen muchas veces antieconómico el arreglo, cuando no totalmente inútil.

El enfoque del sector proveedor debería ser el inverso, por la implicancia en la creación de puestos de trabajo para las reparaciones, y pensar en la vida útil de los productos como una ventaja competitiva para el sector proveedor.

Ambientalmente, importa el pasaje de este tema a una preocupación menor de los proveedores y un incremento del uso excesivo de recursos no renovables. A la vez, acelera la problemática generada por los deshechos de productos manufacturados obsoletos fabricados con materiales no degradables, a lo que se agrega el escaso interés por los componentes recuperables que puedan existir, políticas de reciclado y marketing de durabilidad.

En este marco proponemos que es necesario como primer medida extender la garantía legal de los productos a plazos bastante más largos que los que hoy prevé la ley de defensa del consumidor en su artículo 11 (seis meses para las cosas nuevas y tres meses para las usadas) a los fines de comenzar a modificar las conductas empresarias al respecto, forzando a partir del plazo más extenso al mayor cuidado en la elaboración de los productos, y simultáneamente pautar con amplitud prudente pero necesaria la garantía de servicio técnico y suministro de repuestos (art. 12), que establece la obligatoriedad de los fabricantes, importadores y vendedores de las cosas muebles no consumibles, de asegurar un servicio técnico adecuado y el suministro de partes y repuestos y que hoy aparece por el decreto reglamentario acotada a la vigencia de la garantía, dejando desprotegido el resto de la vida útil -cualquiera sea- del producto, dado que la ley no establece un plazo de vigencia de esta obligación. Creemos en

15 Nota del autor: se ha hablado de introducción deliberada de defectos, piezas frágiles, incompatibilidades con innovaciones y demás estratagemas. 
principio, que como toda responsabilidad poscontractual, la garantía encuentra su límite temporal, como mínimo, en la prescripción quinquenal del artículo 2560 del Código Civil y Comercial, conforme además lo establece la normativa europea. No obstante ello, resulta necesario que se regule sobre la materia, teniendo en cuenta los diferentes bienes en el mercado alcanzados por la garantía.

En un tercer camino, acentuar la rigurosidad en las instrucciones de uso sobre reciclado y reutilización de partes, a cargo del proveedor, que deberá ser obligatoria en productos que contengan elementos ambientalmente nocivos o sean fabricados con componentes desechables de nula o lenta degradación, y sumar a las precisiones obligatorias de las publicidades la obligación de informar la vida útil de los productos conforme parámetros técnicos verificables, y el que resulte relativo al suministro de repuestos. A su vez, el incentivo del estado para los proveedores que reemplacen productos mediante el "rescate" de los que retiran del mercado, es una interesante herramienta.

\section{LA PUBLICIDAD NO DESEADA O INVASIVA:}

Numerosa normativa se ha dictado en la Argentina para proteger la privacidad de las personas ante los posibles abusos del telemarketing ${ }^{16}$. La intimidad es el bien jurídico protegido, lo cual consideramos de importancia, aunque no resulta ser el único involucrado, ya que los derechos comprendidos en la relación de consumo (salud, seguridad, información, etc.) en su etapa precontractual también hallan atención en este tipo de normas, más allá de la privacidad. Están comprendidos entonces el trato digno, el derecho a la información y la regulación de la reciente codificación argentina respecto a la formación del consentimiento y a las ventas a distancia.

Las normas crearon registros que comprenden todos los servicios de telefonía, básica o móvil, en el que pueden optar por inscribirse las personas físicas o jurídicas titulares o usuarias de los servicios alcanzados que manifiesten su voluntad de no ser contactadas por empresas que haciendo uso de datos personales, oferten, regalen o vendan bienes o servicios, sin perjuicio de las previsiones de la ley de Protección de Datos Personales, 25326.

Su objeto es proteger a los titulares o usuarios de telefonía en cualquiera de sus modalidades (telefonía básica, móvil, radiocomunicaciones móviles, IP de voz y cualquier otro que la tecnología proporcione en el futuro, de los abusos del procedimiento de contacto, publicidad, oferta, venta y regalo de bienes o servicios no solicitados

16 Nota del autor: se rige por la ley nacional 26952. En la Ciudad Autónoma de Buenos Aires por la ley 2014 y reformas posteriores, en la Provincia de Buenos Aires la ley 14326, en San Juan la 8052, en Santa Fe ley 13112, y en Neuquén por la ley 2956 entre varias otras. 
Se establece en la generalidad de los casos un sistema de adhesión mediante un proceso gratuito y sencillo, capaz de ser comprendido masivamente, y delega a la reglamentación la puesta en marcha de medios técnicamente aptos para asegurar la autenticidad de la modalidad registral. La inscripción de los que no desean ser llamados (se lo conoce como registro "no llame"), tiene una duración determinada y en general se renueva automáticamente, salvo manifestación en contrario del registrado. A su vez, puede ser cancelada en cualquier momento y sin necesidad de expresar motivo alguno. Se exceptúan las campañas de bien público, las llamadas de emergencia conducentes al resguardo de la salud y seguridad de la población, las campañas electorales, y las de organizaciones sin fines de lucro o realizadas en su nombre. También las llamadas de quienes tienen un vínculo contractual vigente, siempre que se refieran al objeto estricto del vínculo y sean realizadas en forma y horarios razonables.

En esta último caso, aun es necesario que se determine por vía reglamentaria el contexto de "objeto estricto del vínculo" y la razonabilidad del horario, para que no sea paradójicamente interpretado con sentido amplio y posibilitar, por ejemplo, que la titularidad de una simple cuenta sueldo en un banco, habilite la impunidad para ofrecer un sinnúmero de servicios financieros o conexos.

No nos cabe duda que la intromisión de los llamados, la estrategia salvaje de marketing que describimos, la tentativa de venta impuesta, afecta la intimidad de las personas (art. 19 de la Constitución Argentina) y el derecho al trato digno, vulnerando la potestad de los consumidores potenciales de decidir cuándo se someten a los mensajes publicitarios y de determinar por quién y a qué fines pueden ser utilizados datos propios, como el número telefónico.

En nuestro caso, vemos a este régimen de forma muy distinta, desde que se impone al titular de los datos la tarea de preservarse de los atropellos, en lugar de imponerse la obligación genérica de no emitir publicidad no requerida, y habilitar la registración solamente para quienes quieran recibirla, en una verdadera inversión de los términos de la proposición. Es refractario a los principios protectorios del régimen tuitivo consumidor, y a la vigencia de los derechos constitucionales en juego, que deba ser el posible afectado quien deba registrarse para no serlo. El Estado debe aparecer para poner freno a los abusos del mercado, pero tal objetivo no ha de cumplirse imponiendo cargas al consumidor.

\section{LA ATENCIÓN AL CONSUMIDOR: PERSONALIZADA, PRIORITARIA Y SIN ESPERAS:}

La realidad nos muestra la diferencia sustancial - y estratégica - que existe entre la atención y la satisfacción del cliente, entre lo ofrecido, repleto de promesas y beneficios, de rimbombancia, de ostentación publicitaria- y lo realmente entregado, que corresponde al ejercicio diario y constante de una serie de valores corporativo-empresariales que enfrentamos cotidianamente muy a nuestro pesar. Estas se agudizan en los casos de prestatarias más o me- 
nos monopólicas y poco o deficientemente controladas por las entidades estatales, donde su opulencia, su "grandeza", los pactos gremiales y la reducida competencia real los libran de la "pesadilla" o de la carga onerosa de "tener" que prestar un esmerado servicio a esa multitud de clientes que, de todas formas, no van a perder.

Atención personalizada:

Atención personalizada implica relaciones humanas, trato digno, captación del problema, percepción de la tramitación del reclamo ${ }^{17}$. El eje de la interpretación protectoria no es el de la seca gramática que se satisface con que la atención sea dirigida a la persona por cualquier medio, sino que reside en la interacción insustituible que se da entre las personas que actúan en nombre de la empresa y los reclamantes, mediante el contacto humano directo, interpretada en el contexto de la relación de consumo y el desequilibrio entre sus protagonistas. La atención personalizada es una obligación del proveedor, a realizarse en un ámbito de locación específico por éste organizado y proporcionado. Eso requiere necesariamente un lugar físico en vez de un espacio virtual o etéreo. Están involucrados en el caso la dignidad humana y el trato equitativo, para que los consumidores sean tratados de igual manera cuando requieren la contratación del servicio, como cuando acuden a reclamar. Como muy probable consecuencia de estudios de reducción de costos y optimización de beneficios, pero también de aventar reclamos y despejar temperamentos desesperados e inquietos de los consumidores, muchas empresas de distinto nivel han implementado que su modalidad de atención al cliente en materia de reclamos sea únicamente por vía telefónica, o electrónica, con la amabilidad de su gratuidad. Para mayor gentileza en algunos casos puede verse que hasta el teléfono para transmitir y contar el problema se encuentra dentro del establecimiento del proveedor (el termino moderno es "telegestión de reclamos"), donde la principal actividad es otra, sobre todo la venta. En muchos bancos hay seres humanos que cobran impuestos y servicios, reciben depósitos y asesoran sobre préstamos y servicios bancarios de toda laya mediante la presencia personal de empleados/as y elegantes promotores/as, pero sólo voces metálicas reciben y responden los reportes de calamidades.

Por alguna estrategia para nada emparentada con la fidelización o contención del cliente se realiza esta práctica. Cuando la cuestionamos, se nos replica muchas veces que atención personalizada no implica necesariamente presencia humana, sino atención directa y que a través de los servicios telefónicos, los call center suelen solucionar con mucha más rapidez y sin que el consumidor se acerque al establecimiento, los problemas que puedan presentarse. Pero lo cierto es que los seres humanos quedan reservados para atender las actividades comerciales y generadoras de beneficios, quedando los teléfonos para las cuestiones inocuas en rédito, siempre desde el punto de vista empresario. Y he aquí el error, que reside en no comprender que

17 Véase nuestra opinión en Carlos Tambussi, “El humanismo olvidado”, en Microjuris Cita: MJ-7021-AR MJD7021. 
una atención humana y contenedora, arroja un resultado no palpable en números, sino en valores que generan y mantienen clientela, que son la razón de ser de la actividad empresarial.

La cultura vertiginosa y apurada de los servicios, incluye la deshumanización de los reclamos. A las naturales tres dimensiones de las cosas (ancho, alto y espesor) le hemos agregado una cuarta que nos tiraniza: el tiempo, al que tratando de vencer nos sujetamos más y más, siendo cada vez tarde más temprano. $\mathrm{Y}$ en las decisiones empresarias, emerge una quinta dimensión: el precio o el costo en dinero. Un simple ejercicio de "análisis económico del derecho" que realiza el empresario.

Con esa vara se miden desde algunas lógicas mercantiles los sistemas de atención al cliente, aprovechándose de la inercia de la costumbre, que hace que se abandonen los reclamos por cansancio, fortaleciéndose de esa manera la cultura (o subcultura) del mal servicio.

Fue necesario alzarse contra el cierre de las oficinas de atención al público y para que se implemente un efectivo servicio de atención personalizada en las oficinas, tolerada por el propio estado ${ }^{18}$ y quien lo hizo fue una ONG de consumidores, que logro el dictado de medidas cautelares al respecto, y resolución de la Alzada en el pionero precedente "Unión de Usuarios y Consumidores v. CNC - Res. 1763/99 y otros s/proceso de conocimiento" ${ }^{19}$, donde se ratificó la existencia de una obligación legal a la atención personalizada, derivada de los artículos 25 y 27 de la ley de defensa del consumidor.

En 2013, el Juzgado de Faltas Nro 2 de la Ciudad de La Plata ${ }^{20}$, Provincia de Buenos Aires, impuso una importante multa a Telefónica de Argentina, al comprobarse que no proporcionaba atención personalizada a los usuarios del servicio de telefonía básica, remitiendo las consultas y reclamos a su sistema -precisamente- telefónico. El juzgado consideró un derecho de los usuarios el "ser atendidos por personas de carne y hueso", calificando a la práctica empresaria como inadmisible. El Tribunal había actuado de oficio ${ }^{21}$, verificando que la empresa no cumplía con el deber de trato equitativo y digno (Art. 8 bis Ley 24.240) y de atención personalizada (Art. 27), al negarse a recibir reclamos en las sucursales, o solamente hacerlo después de persistencias de los consumidores, con las consabidas esperas. Pese a la defensa empresaria invocando la existencia de la telegestión, y que personas humanas empleadas de la empresa son las que atienden los teléfonos, el decisorio entendió que "es razonable sostener que quien acude personalmente a las Oficinas Comerciales de su

18 Nota del autor: la resolución de la Comisión Nacional de Comunicaciones 1763/1994 consentía la política empresaria de establecer alternativas de reclamos para los usuarios del servicio básico telefónico (por teléfono o por correo) en lugar de las clásicas oficinas comerciales.

19 Cámara de Apelaciones en lo Contencioso Administrativo Federal., sala 3a a, sentencia del 12/08/2010 inédito.

20 Juzgado de Faltas No 2 Juzgado Municipal de Defensa del Consumidor de la Municipalidad de La Plata "Oficina de Defensa del Consumidor s/ Actuación de Oficio c. Telefónica de Argentina (Atención Personalizada) del 4-12-2013 inédito.

21 Conforme Art. 37 de la ley provincial 13133. 
Proveedor de Servicios, lógicamente espera una atención distinta a la que pudo obtener desde su domicilio, desde donde también pueden telegestionar sus quejas y trámites."

El juez interpretó como agravante la posición monopólica de la empresa en su ámbito geográfico y sus niveles de ganancias en los ejercicios anteriores, como fundamentos de la rigurosidad de la sanción aplicada, utilizando el término de "destrato inadmisible" para con los consumidores, en la calificación de la conducta. Ello, en el marco de las claras posibilidades que por su envergadura y poderío económico, la empresa tiene de brindar la necesaria atención personalizada, habiendo deliberadamente aplicado mecanismos que contradicen o desvirtúan esa carga legal. Señala, por último, la gran cantidad de usuarios afectados, frustrados en sus expectativas de trato digno y sometidos a las exigencias de realizar gestiones telefónicas en el centro de atención al cliente.

Más adelante, un juez de la localidad de Gualeguaychú, Provincia de Entre Ríos, aplicó astreintes $^{22}$ o sanciones conminatorias, a la otra empresa prestadora de telefonía básica en forma geográficamente exclusiva (Telecom Argentina S.A), por no cumplir una medida cautelar que ordenaba la apertura de una oficina comercial en esa ciudad, dictada sobre la base de la obligación de garantizar la atención personalizada y gratuita a los usuarios en una oficina comercial abierta a tales fines, con la obligación de informar el lugar, el personal afectado y el sistema que se utilizará. En Junio de 2014 la Sala Civil y Comercial de la Cámara de Apelaciones de Gualeguaychú rechazó el recurso de apelación interpuesto por la empresa contra la medida cautelar. El decisorio previó que se comunique a todos los usuarios afectados la existencia de la acción, y la posibilidad que puedan comparecer personalmente en juicio como partes del proceso, lo cual motivó la adhesión a la demanda de numerosos usuarios de la localidad. La convocatoria ordenada se formalizó mediante la publicación de edictos y avisos en radio y televisión.

La resolución de sanciones conminatorias, fechada 5 de septiembre de 2014 fue dictada en el marco de una causa iniciada por el mismo intendente municipal Juan José Bahillo cuando la demora empresarial llevaba una duración de seis meses al tiempo de su dictado. Reportes periodísticos señalan que el día 23 del mismo mes, Telecom anunció mediante solicitadas en los diarios la apertura de su oficina comercial, que fue inspeccionada por el Municipio constatándose que en el domicilio indicado funcionaba un negocio particular de venta de telefonía celular, con dos escritorios identificados con carteles de Telecom Argentina S.A.

Otras normativas provinciales establecen que las empresas deben contar con oficinas de atención personalizada para que los usuarios puedan efectuar los reclamos en forma personal e informar a los usuarios la localización de esas oficinas ${ }^{23}$.

22 Nota del autor: Por la suma de 200.000 pesos diarios.

23 Véase la ley 14692 de la Provincia de Buenos Aires, la ley 2.221 de la Ciudad Autónoma de Buenos Aires, reformada por ley 4744 (del 26/12/03) y la ley de la Provincia del Chaco 7435, sancionada el 3 de septiembre de 2014. A su vez, la ley 
Es necesario profundizar la consagración legal del deber de atención personalizada, aun admitiendo la existencia de sistemas de reclamos telefónicos que deben ser optativos para el consumidor o usuario, que siempre debe poder acercarse a tratar con una persona humana en un establecimiento. Y que esas normas superen las meras obligaciones de publicar los números en los establecimientos, páginas web o anuncios mediante previsiones que regulen:

- tiempos máximos para contacto directo con el operador.

- el no condicionamiento del suministro de datos para el acceso o la fase inicial de la atención y su exigencia solo en justa medida, al igual que la descripción del objeto del reclamo.

- la efectiva atención de los servicios telefónicos durante las 24 horas.

- la accesibilidad del sistema de reclamos para personas con capacidades diferentes.

- capacitar a los operadores tanto en técnicas de venta como en atención adecuada, lenguaje claro, cordialidad y buena fe.

- registración clasificada, histórica, verificable y accesible de todos los requerimientos y reclamos del consumidor y su reenvío por escrito al reclamante.

- prohibición de la difusión de mensajes publicitarios u ofertas con carácter previo a la atención o espera de la misma.

- conservación de las grabaciones de las llamadas por un tiempo prudencial y el acceso a su contenido por el consumidor en ese lapso.

Atención prioritaria:

Algunos ordenamientos provinciales de nuestro país, como la ley 7800 de la Provincia de Salta obligan comprensivamente a toda dependencia pública o privada que brinde atención al público en cualquier modalidad, a garantizar atención prioritaria y ágil a embarazadas, personas con capacidades diferentes, personas mayores de setenta ańos o con nińos en brazos. La prioridad esta legislativamente determinada excluyéndose la demora en el trámite mediante la espera de un turno, previéndose la implementación de una ventanilla, caja o sector para la atención de las personas comprendidas o preferencias en caso de existir una sola boca de atención.

Las esperas:

Otras normativas regulan el tiempo máximo de espera para toda persona que concurra a los establecimientos públicos o privados de proveedores. Con más intensiva protección otros

nacional 24240 establece: Artículo 27. Registro de Reclamos. Atención personalizada: “...Las Compañias prestadoras de Servicios Públicos deberán garantizar la atención personalizada a los usuarios." 
ordenamientos incluyen a los cajeros automáticos, y el caso del pago de haberes a jubilados y pensionados o trabajadores activos y cobranzas de impuestos o servicios ${ }^{24}$.

Por vía reglamentaria se determina que a los efectos de la determinación del tiempo de espera, la constancia de turno que se brinde al asistente debe indicar fecha y hora de emisión, mas la identificación del establecimiento ${ }^{25}$. Excedido el tiempo de espera, y a pedido del perjudicado, dicha circunstancia deberá ser asentada con firma y sello en el comprobante de turno, donde ha de consignarse fecha y hora de efectiva atención con tiempo excedido, o bien, fecha y hora del retiro del establecimiento sin ser atendido.

La alternativa para el caso de no facilitársele al consumidor esos "asientos certificados" es plasmar el episodio en un libro de quejas, buscando así facilitar implementaciones probatorias para sucesos legalmente previstos y sancionados que muchas veces son difíciles de acreditar.

Las previsiones legales obligan a que se tomen las medidas relacionadas con el trato digno ${ }^{26}$, que prevén la eliminación de la espera en condiciones de incomodidad o a merced del clima y la obligación de sanitarios libres y gratuitos para los que aguardan y la consideración de lesivo a la dignidad de un tiempo de espera mayor de una hora aunque existan asientos e instalaciones sanitarias ${ }^{27}$.

\section{LOS ABUSOS EN LOS PRECIOS:}

Una herramienta ante los aumentos generalizados y los fenómenos inflacionarios es asegurar condiciones de abastecimiento, precio y calidad de bienes y servicios del mercado interno, y desarrollar acciones conducentes a la defensa del consumidor, mediante acuerdos estructurales en relación a los precios de una canasta de productos considerada de consumo masivo, bajo control y seguimiento de la autoridad.

El criterio para dar lugar a posibles revisiones de precios determina que se tendrá en cuenta el impacto en la estructura de costos de la variación de: los precios de venta de los proveedores, costos salariales de distribución y comercialización de los productos, valores de energía y combustible, cargas tributarias y tasas, lo cual implica el reconocimiento normativo del fenómeno inflacionario (incremento de precios de materias primas, consiguiente aumento de costos) y su impacto en las variables fiscales (previendo el aumento de la presión tributaria en general, como efectivamente se produjo).

24 Ley 7780 de la Provincia del Chaco.

25 Ley 7800 de la Provincia de Salta.

26 Otras normativas provinciales asociaron el trato digno con la atención en tiempo razonable: Entre Ríos -art. 5 bis Ley 8973, Ciudad Autónoma de Buenos Aires -Ley 4389-, Misiones -Ley No 4149 y modificatoria No 4329- y Rio Negro -Ley 3669-, entre otras.

27 Ley 7800 de la Provincia de Salta. 
El gran tema es que estos acuerdos suelen prever válvulas de escape, previéndose que por causa justificada o fuerza mayor, el proveedor sea eximido de las obligaciones emergentes del convenio en una determinada zona y por un determinado tiempo. Se han dado déficits en la difusión de los productos beneficiados y en cuanto a la señalización de los productos con precios protegidos en los establecimientos, su distribución en las góndolas en forma separada y aislada, la limitación de cantidad de productos para comprar y la merma de calidad en los productos incluidos en el programa o la reducción de sus dimensiones.

Está discutida la afirmación que la puesta en marcha de mecanismos consensuados acordados o de control de precios mediante valores de referencia se traduzca en verdaderas defensas al consumidor y alivios de bolsillo ante los aumentos de precios excesivos y descontrolados y la consiguiente merma del poder adquisitivo. Comprobar, en suma, si la inflación es un fenómeno de causas estructurales que requiere medidas macroeconómicas y efectos de confianza y credibilidad, o si se la combate o disminuye centralizando exclusivamente en el comercializador final de los productos la responsabilidad de los incrementos de precios, como muchas veces ha sucedido.

Por otra parte, conforme el Art. 1121 del Código Civil y Comercial de la Nación, no pueden ser declaradas abusivas:

a) las cláusulas relativas a la relación entre el precio y el bien o el servicio procurado;

b) las que reflejan disposiciones vigentes en tratados internacionales o en normas legales imperativas.

En cuando al inciso a) consideramos una poco feliz determinación, ya que es en esos casos donde se producen cuantiosas situaciones abusivas, debiéndose haber previsto que la relación pueda establecerse conforme a precios testigo o referenciales de mercado, en lugar de reflejar la idea que los precios surgen razonablemente del libre juego de la oferta y la demanda, es decir que son negociables individualmente, aspecto solamente posible con ese carácter de razonabilidad en un utópico mercado de competencia perfecta y con actores en igualdad de condiciones. Claro está que la relación entre el precio y el bien o servicio puede provocar un desequilibrio significativo entre los derechos y las obligaciones, conforme el Art. 1119 del mismo Código ${ }^{28}$.

En defensa de la previsión que criticamos, se esgrime que lo que se analiza en el "juicio de abusividad" es el desequilibrio normativo y no el económico, y que el aspecto "precio" es factible de ser negociado individualmente, argumentos que entendemos desconocen el senti-

28 Véase Jorge Oscar Rossi, "El nuevo Código y la Protección de los Débiles jurídicos” en Cuadernos de CIJUSO, Fundación de Ciencias Jurídicas y Sociales Colegio de Abogados de la Provincia de Buenos Aires, Nro. 2 Año 1, Diciembre 2014, $58 / 70$. 
do protectorio del régimen tuitivo consumidor e incluso la realidad misma. El desequilibrio económico ha sido receptado por las normas jurídicas desde la formulación misma, por ejemplo, de la teoría de la imprevisión, y la realidad muestra que el consumidor no tiene poder alguno para negociar el precio, situación mucho más embarazosa para él cuando se trata de un producto de primera necesidad y/o de un proveedor en situación de monopolio o de abuso de posición dominante. El consumidor no influye en el mercado, ni en precios, cantidades, condiciones o modalidades de contratación.

Desconocer esa realidad impide vedar a los magistrados considerar al precio como un elemento de abusividad, y sólo se entiende si se privilegian las posiciones de los proveedores en este punto tan sensible, en detrimento de los posibles abusos en los productos y servicios ofrecidos como así también de otras previsiones contenidas en las Leyes de Lealtad Comercial y Defensa de la Competencia, relativas a los productos y servicios ofrecidos en el mercado y al comportamiento de los agentes empresarios que fijen productos excesivos lesionando el trato equitativo y digno que merece el consumidor y desarrollando -en paralelo- prácticas anticompetitivas.

Sobre esta particular norma que brevemente analizamos, cabe traer a consideración que el Código de Consumo de Brasil, en su art. $6 . \mathrm{v}^{29}$, instituye específicamente la posibilidad de modificación de las cláusulas contractuales que establezcan prestaciones desproporcionadas.

Por lo demás, entendemos que esta previsión, tiene más relación de aplicabilidad en economías estables ${ }^{30}$, ajenas a nuestra permanente fluctuación y cultura inflacionaria, que ha llevado a que sea necesario fijar sea controles de precios, sea sujeción de aumentos de prestaciones a pautas establecidas en la misma normativa (caso de la ley de Medicina Prepaga 26682 Art. 17) ${ }^{31}$, no así en nuestra realidad económica y crediticia, donde impedir la declaración de abusividad con relación al precio de un servicio cobra -en el caso por ejemplo de los consumidores financieros- una limitación írrita al ser un obstáculo para la usura y un impedimento para la proliferación del sobreendeudamiento del consumidor, que necesita del crédito para acceder a posibilidades de ciertos consumos.

29 El art. 6. V del Código de Defensa del Consumidor de Brasil establece: "Son derechos básicos del consumidor:...V. La modificación de las cláusulas contractuales que establezcan cuotas desproporcionadas o su revisión en razón de hechos supervenientes que las hagan exageradamente onerosas".

30 Nota del autor: la Directiva 93/13 de la Unión Europea establece que "la apreciación del carácter abusivo no debe referirse ni a cláusulas que describan el objeto principal del contrato ni a la relación calidad precio de la mercancía o de la prestación".

31 Véase Carlos Ghersi, "Inaplicabilidad de los arts. 973 y 1121 del Código Civil y Comercial de la Nación a los contratos y relaciones de consumo", en Microjuris, cita: MJ-DOC-7218-AR. 


\section{CONCLUSIONES Y PROPUESTAS:}

El derecho de usuarios y consumidores viene a igualar, a proteger, y no a terminar con la ganancia empresaria, a la que siempre va a considerar legítima mientras no se haga a costa del más débil.

Una visión empresaria integradora y social, debería concluir en que cumplir con la ley y honrar los derechos protegidos por el régimen tuitivo consumidor es la mejor estrategia para fidelizar su política de comercialización, prestigiar su marca y su servicio, en lugar de una gracia del poderoso que puede o no darse. Entenderemos esto como asumido el día en que esta disciplina sea internalizada en las planificaciones empresarias, en validez, vigencia y acatamiento de las normas, sin temor a nuevos institutos protectorios solo aplicables en caso de incumplimientos, violaciones a la buena fe o trato indigno, que como grupo económico siempre reclaman como motores de la economía y agentes del mercado que se consideran

Veremos esto realizado en el momento en que puedan verse en conjunto las ventajas de consolidar la doctrina y el desarrollo de estos derechos, auspiciando a nivel empresa encuentros y jornadas donde se pongan en debate (cuestión que hoy solo se motoriza a través de universidades, ONG y entidades profesionales) y se formen los abogados empresariales o abreven los estudios jurídicos que las asesoran en las nociones protectorias y sociales de consumidores y usuarios, para que en la consulta y asesoramiento a gerentes y directivos brinden el contenido necesario desde el punto de vista jurídico para evitar a la empresa asesorada confrontar con la norma tuitiva. Podrían también, acompañar en la brega por consolidar la consideración como consumidores de las personas jurídicas, y en el afianzamiento de sistemas agiles y económicos para la solución de conflictos como por ejemplo el arbitraje de consumo, adhiriendo a la oferta pública, y anunciando en su publicidad la adhesión y la posibilidad de dirimir conflictos en forma sencilla, y sobre todo, dejar de lado el análisis económico de las consecuencias jurídicas de un comportamiento empresario, estando en juego derechos fundamentales de los consumidores ${ }^{32}$.

Sin dejar de lado la brega por consolidar los derechos del consumidor, queremos extractar de la doctrina española ${ }^{33}$ una serie de principios que una buena política empresaria debería

32 Uno de los casos más famosos de la jurisprudencia estadounidense, que de alguna manera originara la aplicación de los llamados "daños punitivos" , es "Grimshaw vs. Ford Motor Co." de 1981. El mismo se origina cuando un rodado fabricado por la demandada se incendia a causa de un grave defecto de fabricación en cuanto a la ubicación del tanque de combustible, que facilitaba la explosión en caso de choque con impacto o incidencia en la parte trasera. Se comprobó que el fabricante conocía ese defecto, con miles de unidades vendidas, y que su cálculo había sido que resultaba más económico indemnizar a las victimas de los eventuales hechos, que reparar o retirar todos los rodados Un ejemplo más de cómo nos deshumaniza el análisis económico del derecho. Economicismo puro y desprecio de los valores humanos han dado sobrados ejemplos de ir siempre de la mano.

33 Adaptación nuestra con agregados propios de un artículo de Juan Carlos Díez Posada: degerencia.com, acceso el 19 de febrero de 2018 http://www.degerencia.com/articulo/declaracion_universal_de_los_derechos_de_los_clientes).Datos 
implementar para saber diferenciar servicios de alta calidad de aquellos que no persiguen otra cosa que "atrapar" a un cliente para luego administrarlo de cualquier modo.

a) La empresa debe conocer que el consumidor tiene derecho a no saber. Y por ende a no ser recriminado y maltratado por no estar enterado de uno o más aspectos de la mecánica operativa de la compañía que les presta un servicio. Es deber de la compañía presentar información veraz, completa, oportuna y por los canales más adecuados a sus clientes. A la vez, es su deber aplicar un significativo esfuerzo económico y logístico en el entrenamiento y capacitación de todo el personal — no sólo de los asesores o el personal de servicio- en técnicas de escucha activa, talento para formular preguntas y plantear soluciones, estudio periódico de la casuística del negocio y estrategias para conducir al cliente a la satisfacción.

b) El consumidor tiene derecho a hacer sugerencias, preguntar, a desconfiar, a replicar y a comparar. A ser tratado igual si va a consumir o a reclamar. A que sea respetado su tiempo y sus condiciones. A tratar con una persona humana. A tener medios que no sean informatizados para realizar su gestión o contratación.

c) El tiempo del consumidor es sagrado: (tan valioso como el de la compañía). Con los recursos y herramientas de que disponemos en la actualidad, es imperdonable que no exista una configuración estratégica destinada a ofrecer calidad de servicio en términos de velocidad de respuesta y ahorro de tiempo.

d) El consumidor tiene derecho a ser bien atendido antes, durante y mucho después de la venta. La posventa profesional y el seguimiento al cliente es una práctica que se considera "costosa”, prescindible a los ojos de muchos gerentes. "¿Para qué molestarnos, para qué aplicar esfuerzos en alguien que ya nos dio lo que buscábamos?”.

e) El consumidor tiene derecho a obtener soluciones prontas. Muchas empresas usan disuasivos para los reclamos sabiendo que son pocos los consumidores dispuestos a movilizarse e ir a la lucha judicial y/o administrativa para defensa de sus derechos. Por eso persisten en el error de no implementar estrategias conciliatorias y compensatorias que les permitan salir pronto de la situación de conflicto. La figura del defensor del cliente, nombrado para tal fin dentro de las mismas empresas, es una solución inteligente para mantener e incrementar la confianza en los procedimientos y las actuaciones de las compañías, pero que debe ganarse la credibilidad de quienes dice representar, o de lo contrario se convertirá en otro montaje más para eludir responsabilidades.

f) Y en lo estructural, en definitiva la cuestión es construir un concepto de responsabilidad social empresaria sobre la base del cumplimiento de la ley y la ética, que englobe una

del autor en (http://www.degerencia.com/juandiez). 
gestión de la empresa que debe tener en cuenta no solo los intereses comunes de sus socios y/o sus inversores sino los intereses de todas las personas o grupos que podrían verse afectados por la actividad de la sociedad, y aquí es donde talla el concepto de interés social que comprende no solo el interés económico de los accionistas sino también el interés de la sociedad en general, que los administradores deben llevar a la práctica.

La responsabilidad social empresaria es complementaria, forma un conjunto con los derechos de usuarios y consumidores. Su concientización es el primer remedio contra la persistencia de las prácticas abusivas en los seńeros ejemplos que desarrollamos en este trabajo.

\section{REFERENCIAS}

- Álvarez Larrondo, Federico Manuel "Ley 27.250: El deber de información en soporte papel", DPI Cuántico. Diario Consumidores y Usuarios Nro. 79, 21.06.2016

- Arias Cáu Esteban y Barocelli, Sergio Sebastian "El sobreendeudamiento del consumidor y la adicción al consumo", en Microjuris Cita: MJ-DOC-6461-AR | MJD6461

- De Lorenzo, Miguel F., "Contratos, derechos fundamentales y dignidad de la persona humana”, La Ley 2011-E, 1258.

- Díez Posada Juan Carlos, degerencia.com, acceso el 19 de febrero de 2018 http://www. degerencia.com/articulo/declaracion_universal_de_los_derechos_de_los_clientes).Datos del autor en (http://www.degerencia.com/juandiez).

- García Canclini, Nestor Consumidores y Ciudadanos, conflictos multiculturales de la globalización (Grijalbo, México, 2000).

- Ghersi, Carlos Alberto "Inaplicabilidad de los arts. 973 y 1121 del Código Civil y Comercial de la Nación a los contratos y relaciones de consumo", en Microjuris, cita: MJ-DOC-7218AR.

- Kemelmajer de Carlucci, Aida "Prácticas abusivas en los contratos de consumo", Suplemento Especial Esp. Nuevo Código Civil y Comercial de la Nación. Contratos 2015 (febrero), 237.

- Rossi, Jorge Oscar "El nuevo Código y la Protección de los Débiles jurídicos" en Cuadernos de CIJUSO, Fundación de Ciencias Jurídicas y Sociales Colegio de Abogados de la Provincia de Buenos Aires, Nro. 2 Año 1, Diciembre 2014 pp. 58/70. 
- Tambussi, Carlos, Araldi Liliana y Baigorria Mariana,"La responsabilidad social empresaria $y$ los derechos del consumidor", Diario La Ley 6 y 7 de enero de 2014. Cita On Line: AR/ DOC/3999/2013.

- Tambussi, Carlos "Del soporte electrónico y la forma en los contratos a distancia" DPI Cuántico. Diario DPI Consumidores y Usuarios Año 2, No 50, 20 de octubre de 2015.

"Sobre la necesidad de actuar ante el fenómeno de la obsolescencia programada" en elDial cita DC202C.

"El humanismo olvidado", en Microjuris Cita: MJ-7021-AR MJD7021.

Recibido: 19/02/2018

Aprobado: 23/04/2018 